\title{
Proline-dependent regulation of collagen metabolism
}

\author{
Ewa Karna ${ }^{1} \cdot$ Lukasz Szoka $^{1} \cdot$ Thi Yen Ly Huynh ${ }^{1}$. Jerzy A. Palka ${ }^{1}$
}

Received: 4 April 2019 / Revised: 17 October 2019 / Accepted: 30 October 2019 / Published online: 18 November 2019

(C) The Author(s) 2019

\begin{abstract}
This review is focused on recent data on the role of proline (Pro) in collagen biosynthesis and cellular metabolism. It seems obvious that one of the main substrates for collagen biosynthesis Pro is required to form collagen molecule. The question raised in this review is whether the Pro for collagen biosynthesis is synthesized "de novo", comes directly from degraded proteins or it is converted from other amino acids. Recent data provided evidence that extracellular Pro (added to culture medium) had significant, but relatively little impact on collagen biosynthesis in fibroblasts (the main collagen synthesized cells) cultured in the presence of glutamine (Gln). However, extracellular Pro drastically increased collagen biosynthesis in the cells cultured in Gln-free medium. It suggests that Pro availability determines the rate of collagen biosynthesis and demand for Pro in fibroblasts is predominantly met by conversion from Gln. The potential mechanism of this process as well as possible implication of this knowledge in pharmacotherapy of connective tissue diseases is discussed in this review.
\end{abstract}

Keywords Amino acids $\cdot$ Prolidase $\cdot$ Collagen $\cdot$ Cell metabolism $\cdot$ Signaling

\section{Transcriptional regulation of collagen biosynthesis}

Gene expression and protein synthesis are regulated in several stages: at the DNA level by changing the degree of chromatin packing, during transcription regulated by specific transcription factors, at posttranscriptional level due to modification of mRNA stability, and also during translation, the initiation of which is a controlled process [1]. The posttranslational modification stages are also of great importance for the efficiency of collagen biosynthesis, because deregulation of this process leads to the formation of abnormal collagen molecules that may undergo intracellular degradation [2]. For instance ascorbic acid is necessary for the hydroxylation of prolyl and lysyl residues, whereas lysyl

Jerzy A. Palka

pal@umb.edu.pl

Ewa Karna

ewa.karna@umb.edu.pl

Lukasz Szoka

lukasz.szoka@umb.edu.pl

Thi Yen Ly Huynh

ly.huynhthiyen@umb.edu.pl

1 Department of Medicinal Chemistry, Medical University of Bialystok, Mickiewicza 2 D, 15-222 Białystok, Poland oxidase requires the presence of $\mathrm{Cu}^{2+}$ ions [3, 4]. Changes in the intensity of collagen biosynthesis are the result of the regulation of the mRNA level by ascorbic acid [5]. Copper deficiency impairs the collagen cross-linking process, without affecting the value of biosynthesis [6]. Growth factors in a differentiated way affect the biosynthesis of collagen. Epidermal growth factor (EGF) impairs the transcription of collagen genes and reduces the stability of mRNA and stimulates the proteolysis of collagen by increasing the expression of collagenase [7]. Inhibitory effects at the transcription level are also manifested by fibroblast growth factor (bFGF), while the effect of platelet derived growth factor (PDGF) activity is dependent on the isoform of this dimeric protein $[8,9]$. Strong inducers of collagen biosynthesis are insulinlike growth factor-I (IGF-I) and transforming growth factor $\beta 1$ (TGF- $\beta 1$ ) [10]. TGF- $\beta 1$ stimulates the transcription of not only collagen but also other cellular proteins, and IGF-I has a greater preference for collagen in this respect $[5,10$, 11]. Basic mediators of inflammation, i.e., interleukin 1 and tumor necrosis factor- $\alpha$ (TNF- $\alpha$ ), as well as interferon- $\gamma$, impair collagen biosynthesis $[12,13]$. This action, at least to some extent is mediated by the p50/p65 heterodimer of the NF- $\mathrm{KB}$ transcription factor, inhibiting the transcription of the genes of both collagen-type I-forming chains [12, 14, 15]. Inhibition of collagen biosynthesis by NF- $\mathrm{KB}$ activation is a common mechanism of action for both physical agents 
and chemical substances [16, 17]. Biosynthesis of collagen is also subject to hormonal regulation. Insulin acting via IGF-IR, progesterone and androgens stimulate this process, whereas the opposite effect is exerted by glucocorticoids $[10,18-21]$.

The interaction of collagen with integrin receptors may also contribute to changes in the expression of this protein. A signal from the $\alpha 1 \beta 1$ receptor inhibits collagen biosynthesis based on the principle of negative feedback [22]. The $\alpha 2 \beta 1$ receptor plays an opposite role, stimulating transcription of the type I collagen gene [23].

\section{Sources of proline for collagen biosynthesis}

Proline constitutes about $10 \%$ of total amino acids (AAs) in collagen, which accounts for one-third of proteins in mammals [24]. As the most abundant protein in the body, collagen is essential to maintain the proper structure and strength of connective tissue, such as bones, skin, cartilage, and blood vessels. The support of proline is required for biosynthesis of collagen as well as other proline-containing proteins. Therefore, regulation of proline availability for collagen biosynthesis is critical to maintain tissue integrity as for instance during wound healing [25]. In some recent studies it was found that endogenous synthesis of proline is insufficient for maximal growth and collagen production [26]. Proline handling is at least partially dependent on the route of administration; the small intestine takes up considerable loads of dietary proline [27]. It was well established that supply of Pro is essential for the biosynthesis of collagen. The knowledge comes from the experiment showing that proline analogues suppress collagen expression. The mechanism of proline analogues competition with Pro in collagen biosynthesis is well recognized [28]. However, impaired ability of fibroblasts to synthesize Pro was also shown in the cells incubated in medium without glutamine (Gln) $[29,30]$. Mammals can synthesize proline from arginine, glutamine and glutamate and the process is regulated by glucocorticoids [31]. However, an addition of exogenous Pro reversed this effect presumably as a result of competition mechanism [32].

Recent clinical and preclinical data suggested that arginine (Arg) and ornithine (Orn) supplementation are the most effective in increasing collagen deposition. However, whether this was accomplished by conversion to proline has not been confirmed [25, 33]. It is known that glutamine plays a key role in protein metabolism. Therefore, glutamine is considered as a regulatory amino acid of proline availability for collagen biosynthesis [34].

\section{Sources of free proline for cellular metabolism}

Pro is formed from glutamate (Glu) which is produced from Gln. The main source of Gln in the body is Glu in muscle that is converted to Gln by glutamine synthase. The enzyme is widely distributed in tissues and was reported also in fibroblasts [35]. Glu metabolism is catalyzed by 1-pyrroline5-carboxylate (P5C) synthase and P5C reductase with P5C as an intermediate product that links the citric acid and urea cycle (Fig. 1).

P5C is formed from both Glu and Pro, due to interconvertibility of this amino acid [36, 37]. P5C can be converted back to proline via P5C reductase in the presence NADPH in a reaction that is favored when collagen production is increased. This reaction is coupled to pentose phosphate pathway contributing to synthesis of purine nucleotides for DNA biosynthesis [38]. Alternatively, P5C is interchangeable with a number of amino acids and metabolites through a variety of transformations linking the citric acid and urea

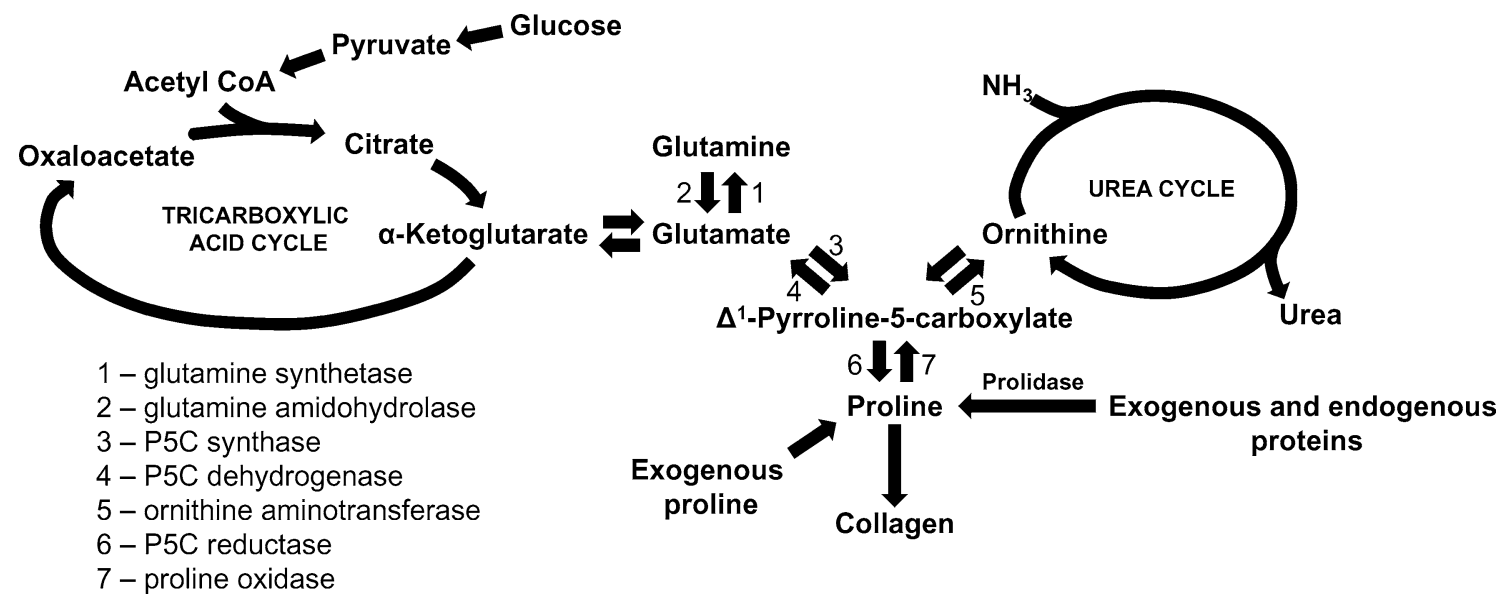

Fig. 1 Amino acid interconversions and functional links between the tricarboxylic acid and urea cycles in collagen biosynthesis 
cycles. Arg and Orn play a particular role in interconversion of proline, P5C and glutamate [39]. Arg is converted to Orn through the irreversible final step in the urea cycle. Subsequently, Orn can be converted to P5C by the action of ornithine aminotransferase (OAT). The action of OAT is readily reversible and is dependent on the availability of both substrate and products. Thus, when intracellular Orn concentration is low, the pathway is favored toward Orn. Conversely, increased Orn concentration promotes production of P5C for Pro, Glu or Gln biosynthesis [40]. The production of proline from Orn mediates a transfer of reducing potential from cytosolic NADPH to mitochondrial NAD ${ }^{+}$.

"De novo" proline synthesis for collagen biosynthesis is unfavorable energetically. When Pro is produced from Glu two molecules of NADPH are oxidized, one in mitochondria and one in cytosol. The oxidation requires 6 mol of ATP per mol of product only in mammals [26]. The synthesis of Pro from Gln requires $8 \mathrm{~mol}$ of ATP/mol of product, Arg to Pro (in all animals): $2.5 \mathrm{~mol} / \mathrm{mol}$ product [26]. The conversion of Glu to Orn also requires ATP which is produced during transfer of reducing potential within mitochondria from NADPH to NAD ${ }^{+}$[32] (Fig. 1). Therefore, in cancer cells that frequently undergo Gln starvation arginine transporter expression as well as intracellular arginine level are significantly increased [30] presumably as an alternative source of proline to support growth and protein synthesis. The data were corroborated by studies of Wu et al. [41] showing dietary requirement of proline, arginine and glutamate for daily growth rate in young pigs.

Another source of Pro is imidodipeptides hydrolyzed by prolidase [E.C.3.4.13.9]. This enzyme plays an important role for supplying proline for collagen biosynthesis [42]. However, the marginal role of prolidase for proline support was observed in the specific cellular culture conditions in Gln-free medium [29].

\section{Function of proline in cellular metabolism}

Pro as a product of prolidase-catalyzed reaction has an impact on the action of transcription factors. In fact Pro was shown as a HIF-1 $\alpha$-inducing agent in colon cancer RKO cell line [43]. Pro was found to inhibit hydroxylation of specific proline residue in the oxygen-dependent degradation (ODD) domain of HIF-1 $\alpha$, thus preventing targeting of HIF- $1 \alpha$ for ubiquitination and proteasomal degradation [44]. Since RKO cells utilize proline by proline oxidase (POX) [45], HIF-1 $\alpha$ expression is low in the cells. On the other hand in fibroblasts (the cells showing low expression of POX) the expression of HIF- $1 \alpha$ is relatively high. It seems that, upregulation of HIF- $1 \alpha$ does not depend on the effect of metabolites of Pro. This process is upregulated in the absence of Gln [46] that in fibroblasts is converted to Glu and $\alpha-K G$. It was found that Gln deprivation contributed to decrease in the concentration of $\alpha-\mathrm{KG}[47,48]$ and the cells become more susceptible to the stabilizing effect of proline on HIF- $1 \alpha$, as shown on Fig. 2.

However, we found that Pro analogues downregulated HIF-1 $\alpha$ expression in fibroblasts and prevented its upregulation by proline addition. Of special interest is observation that, proline analogues did not affect Pro-dependent upregulation of collagen expression in fibroblasts. The data suggest that this process is not dependent on HIF-1 [29].

Since proline upregulates HIF- $1 \alpha$ transcription factor that induces expression of several pro-survival genes, it has been speculated that increase in proline degradation by POX could contribute to pro-apoptotic phenotype of cells. In fact p53 is inducer of POX expression [45, 49]. The mechanism for regulation of POX by p53 was found in the POX promoter, containing a p53-response element [50]. However, in fibroblasts proline did not affect POX expression. Moreover, increased expression of p53 did not affect cell viability suggesting that apoptosis is not induced in these cells.

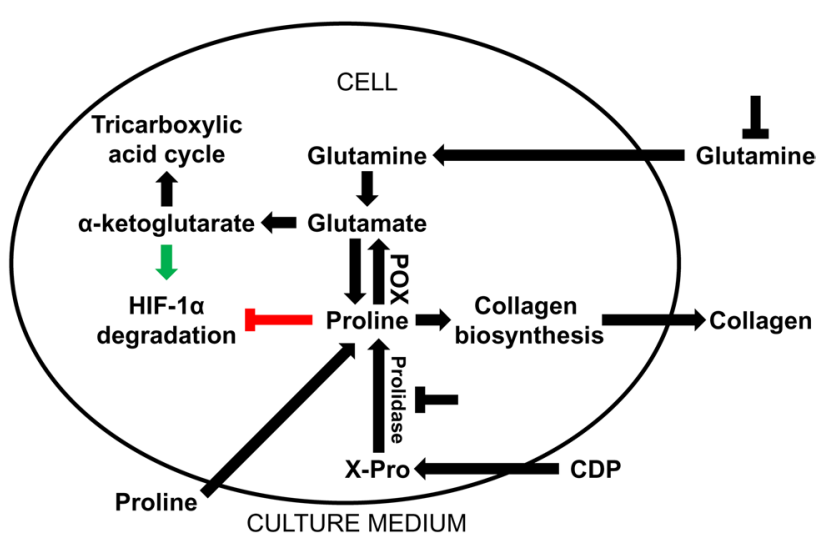

Fig. 2 The role of exogenous proline in regulation of collagen biosynthesis and HIF-1 $\alpha$ expression in cultured fibroblasts. Glutamine of culture medium is converted in the cells into glutamate and $\alpha$-ketoglutarate, intermediate of tricarboxylic acid cycle. Glutamate is also converted to proline, substrate for collagen biosynthesis that maintain high collagen biosynthesis rate. Exogenous proline slightly contributes to increase in collagen production. Glutamine deprivation decreases cellular proline content resulting in downregulation of collagen biosynthesis. In this condition, exogenous proline restores intracellular proline pool, providing substrate for collagen biosynthesis. Due to low expression of proline oxidase (POX) in fibroblasts the conversion of proline into glutamate is marginal. Moreover, prolinedependent regulation of HIF- $1 \alpha$ transcriptional activity is more pronounced in the absence of glutamine since $\alpha$-ketoglutarate induces HIF- $1 \alpha$ hydroxylation and its ubiquitin-dependent degradation. In the absence of glutamine, $\alpha$-ketoglutarate production is impaired, contributing to upregulation of HIF- $1 \alpha$ transcriptional activity. In the presence of glutamine, proline-induced HIF- $1 \alpha$ transcriptional activity is attenuated. $C D P$ collagen degradation products, $X$-Pro imidodipeptides, $P O X$ proline oxidase, $H I F-1 \alpha$ hypoxia inducible factor- $1 \alpha$, potential targets of collagen biosynthesis regulation 
Of interest is that the IGF-I signaling is involved in Prodependent stimulation of intracellular collagen expression [29]. IGF-I has well established potency to stimulate collagen biosynthesis $[18,51]$. The mechanism of this process was found at the level of prolidase activity, the enzyme supporting proline for protein biosynthesis [42]. Moreover, products of prolidase catalytic activity, Pro and hydroxyproline (HyPro) induced increase in the amount of TGF $\beta 1$ receptors. Therefore, it has been suggested that it may act as an interface between mTOR and phospho-mTOR in regulation of numerous TGF $\beta$ receptor-dependent functions, including regulation of collagen biosynthesis [52].

\section{Role of proline and glutamine in regulation of collagen biosynthesis}

Gln induces collagen gene transcription [53]. Culture medium (DMEM) contains high concentration of Gln $(4 \mathrm{mM})$ that is proline convertible amino acid supporting intracellular pool of Pro. It was found, that in fibroblasts Gln deprivation diminished collagen expression, while Pro counteracted this effect. The role of proline in this process cannot be linked to its conversion to Gln because activity of POX in fibroblasts is very low. Therefore, Gln deprivation impairs Pro biosynthesis contributing to relative proline deficiency. Of interest is that it was partly normalized by Pro supplementation [29]. In fibroblasts cultured in glutaminefree medium (showing very low expression of collagen) Pro induced collagen expression by about twofold, while in the medium only by about $30 \%$, compared to control. It suggests that shortage of Gln favors exogenous Pro as a substrate for collagen biosynthesis. Nevertheless, only small amount of synthesized collagen is secreted outside the cell. However, in fibroblasts cultured in Gln-supplemented medium (showing high expression of collagen) exogenous Pro upregulated collagen expression only by $30 \%$ without significant secretion of this protein into medium [29]. It suggests that exogenous Pro has lower than Gln influence on collagen biosynthesis. Recently we found that Pro deficiency resulting from a lack of Gln may be partly supplemented by recovery of Pro from imidodipeptides, intermediate products of protein degradation [54]. Thus, it can be concluded that fibroblasts prefer exogenous Gln, as an intermediate of proline for effective collagen biosynthesis. The data are supported by recent studies showing that glutamine is indispensable for conversion into Pro (but not into $\alpha$-ketoglutarate) to support collagen protein biosynthesis [55]. Moreover, it was found that intracellular concentration of Pro was drastically decreased after Gln withdrawal [30].

Although several lines of evidence suggest that Pro is conditionally essential amino acid that must be present in diet to support collagen biosynthesis, recent studies provided evidence that glycine is as well as important in diet to satisfy the demands for the process [56]. However, it has been found that milimolar concentration of glycine is required to enhance type II collagen in bovine chondrocytes, while Pro and lysine evoked the effect at physiological concentrations [56].

Some studies considered proline-dependent regulation of $\mathrm{NF}-\mathrm{\kappa B}$. It was documented that increase in prolidase activity contributed to increase in NF-kB p65 expression [42]. This transcription factor is important for collagen type I biosynthesis, since transcription of genes coding type I collagen subunits is inhibited by NF-KB $[12,14,57]$. However, extracellular Pro did not affect expression of NF- $\mathrm{\kappa B}$ in fibroblasts.

It has been found that exogenous glutamine induced collagen biosynthesis $[58,59]$. However, in our recent data we showed that collagen biosynthesis was not suppressed completely in fibroblasts growing in Gln-deprived medium. Therefore, it seems that the effect can be associated with synthesis of Gln/Glu and recycling of Pro by prolidase. Pro is converted in mitochondria by POX to P5C and further to Glu, Orn, or again back to proline. The proline cycle is considered as a potential target for cancer therapy [34, 60], while metabolism of glutamine in the new therapeutic approach to the treatment of liver fibrosis [61].

POX is expressed ubiquitously in the body, but POX activity was found previously to be undetectable in fibroblasts [62]. In our recent studies we noticed trace expression of POX in these cells, suggesting that proline in fibroblasts is mainly consumed for protein biosynthesis [29]. However, it seems that in standard conditions, extracellular proline has little impact on upregulation of collagen biosynthesis.

The results of these studies allow to conclude that availability of glutamine, as a substrate for proline biosynthesis represent limiting factor for utilization of exogenous proline for collagen biosynthesis [29]. The conclusion is supported by other authors, showing that an addition of proline has failed to increase collagen biosynthesis in fibroblasts and other cells [58, 63-65].

\section{Prolidase in pathobiochemistry and experimental pharmacotherapy of connective tissue diseases}

Prolidase is the only enzyme that hydrolyzes imidodipeptides with C-terminal proline. The role of imidodipeptidesderived proline for collagen resynthesis is well established, particulary in respect to the action of some drugs. For instance, captopril is structurally similar to imidodipeptides having L-proline as the $\mathrm{C}$-terminal position. As a competitive inhibitor of prolidase interferes with collagen metabolism [66-69]. During therapy with this drug dermatological manifestations are observed. However, treatment of patients with 
enalaprilat, metabolite of captopril gave a lower incidence of dermatological symptoms than those with captopril [70, 71].

In respect to other drugs it was found, that non-steroid antiinflammatory drugs, doxycycline, anthracyclines and plant-derived compound [(Z)-8,9-epoxyheptadeca-1,11,14triene] coordinately inhibited the metabolism of collagen and prolidase activity in fibroblasts [72-75].

In contrast, butyrate, hyaluronic acid, hydralazine, oxythiamine and flavonoid glycosides increased collagen biosynthesis in cultured human skin fibroblasts that resulted from activation of prolidase activity [76-80].

The functional significance of the correlation between prolidase activity and collagen biosynthesis was found in several diseases. For instance an increased activity of liver prolidase was found during the fibrotic process [81]. There was also a positive correlation between prolidase activity and fibrosis in lung [82]. A significant increase in serum prolidase activity was observed in patients with hypertension, which was interpreted as evidence of increased collagen degradation with a higher collagen turnover rate in hypertension tissues, contributing to left ventricular hypertrophy [83].

On the other hand the deficiency of proline in the tissues caused abnormal collagen production and negatively affected clinical healing. Consequently, the ability to form normal granulation tissue was impaired [84]. The most serious disease is prolidase deficiency (PD). The symptoms of the disease are: chronic leg ulcers and recurrent infections, as a result of disturbances in biosynthesis of immunoglobulins and $\mathrm{C} 1 \mathrm{q}$, systemic accumulation of iminodipeptides with C-terminal proline or hydroxyproline, which subsequently get excreted in massive amounts in the urine, depleting the total pool of proline [85]. It has been speculated that the defect in the re-utilization pathway of proline leads to a relative deficiency of proline in the tissues, which may cause abnormal collagen production and negatively affect healing.

In many cases, congenital prolidase deficiency is also accompanied by mental retardation. It may result from lower levels of L-proline in the CNS. It is known that L-proline plays an important role in stimulating glutamatergic neurons. Probably the biggest role in this process could play prolidase of erythrocytes. It is known that imidodipeptides (e.g., glicylo-L-proline) demonstrate the ability to penetrate the erythrocytes, where under the influence of prolidase are degraded to free amino acids. Due to the fact that erythrocytes do not utilize amino acids to their own life processes, can be assumed that with the help of prolidase they take an active part in the secretion of amino acids derived from imidodipeptides. Prolidase deficiency reduces the concentration of L-proline in the circulation, which may interfere with the above-mentioned function of glutamatergic neurons.

There is no effective treatment for PD. Many experimental approaches have been made without success. Oral supplementation of L-proline has been given to patients with minor results [86]. The topical application of a mixture of proline and glycine has given better result [87-89], however, some authors reported no benefit at all $[88,90]$.

Prolidase is not the only enzyme that recovers proline from imidodipeptides. Another one is prolinase (E.C.3.4.13.8), termed "human cytosolic non-specific dipeptidase" that recovers proline from Pro-X dipeptides. The activity of prolinase and prolidase is different in some diseases [91, 92].

The data suggest that external application of proline alone or in form of imidodipeptides is not effective to achieve proline-dependent function. It seems that intracellular process of proline and collagen metabolism plays critical role in maintaining cellular homeostasis. It has been demonstrated in several models of drug-treated fibroblasts.

The mechanism of drugs-dependent regulation of collagen biosynthesis and prolidase activity was found at the level insulin-like growth factor-I receptor (IGF-IR), $\beta 1$-integrin receptor $[93,94]$ and NF- $\mathrm{KB}$ signaling $[78,95]$.

While stimulation of IGF-IR and $\beta 1$-integrin receptor induced collagen biosynthesis and prolidase activity, the $\mathrm{NF}-\kappa \mathrm{B}$ was inhibitory for these processes. In fact NF- $\mathrm{KB}$ is transcriptional inhibitor of genes for type I collagen subunits [12]. Some experiments revealed indirect correlation between collagen biosynthesis and prolidase activity and expression. For instance, studies on the mechanism of inhibition of collagen biosynthesis by camptothecin showed that underlying process is stimulation of NF- $\mathrm{kB}$-dependent signaling pathway. However, in the course of experiment we observed increased prolidase activity and expression of $\beta 1$-integrin receptor that activates NF- $\mathrm{BB}$ [95].

Similar mechanism was observed for the inhibitory effect of scutellarin (Scut) on collagen biosynthesis [17]. This flavonoid is a component of the currently examined anti-infarct prodrugs. It was found that a SCUT-dependent decrease in collagen biosynthesis in cultured human skin fibroblasts was accompanied by an increase in prolidase activity and resulted from activation of NF- $\mathrm{kB}$, which is responsible for downregulation of collagen gene expression.

It cannot be excluded that critical role in proline-dependent functions play glycolysis. In fact, phosphoenolpyruvate (PEP) is known as a prolidase activity inhibitor "in vitro" [67]. It was found that PEP-dependent decrease in prolidase activity and expression was accompanied by parallel decrease in collagen biosynthesis [96].

\section{Conclusion}

Deregulation of proline metabolism is underlying mechanism of some connective tissue diseases. Proline plays an important role in regulation of gene expression, transcription factors, mTOR cell signaling, cellular redox reactions, 
synthesis of ornithine, arginine, polyamines, glutamate and collagen. However, it is only single player in complex regulatory machinery of cellular metabolism that determine the source of Pro availability for collagen biosynthesis dependently on the metabolic context. Since Gln shortage is a very rare phenomenon therefore supplementation of proline to counteract collagen metabolism defects has minor effectiveness. More study has to be done to understand the mechanism of proline-dependent functions.

Acknowledgements Conducted with the use of equipment purchased by Medical University of Bialystok as part of the OP DEP 2007-2013, Priority Axis I.3, contract No. POPW.01.03.00-20-022/09.

Author contributions EK conceived, edited and wrote the paper; LS prepared the images and wrote the paper; TYLH performed the literature search; JP designed and critically edited the paper.

Funding This work was supported by the Medical University of Bialystok (Grant N/ST/ZB/17/001/2214), European Union's Horizon 2020 research and innovation programme under the Marie Skłodowska-Curie Grant Agreement No. 754432 and Polish National Science Center No. 2017/25/B/NZ7/02183

\section{Compliance with ethical standards}

Conflict of interest The authors declare no conflict of interest.

Author agreement It is to certify that authors of this paper have read and approved the final version of the manuscript. They declare that the article is the authors' original work and has not been sent for publication elsewhere.

Open Access This article is distributed under the terms of the Creative Commons Attribution 4.0 International License (http://creativeco mmons.org/licenses/by/4.0/), which permits unrestricted use, distribution, and reproduction in any medium, provided you give appropriate credit to the original author(s) and the source, provide a link to the Creative Commons license, and indicate if changes were made.

\section{References}

1. Marks A, Lieberman MA, Peet A (2013) Marks' basic medical biochemistry: a clinical approach, 4th edn. Wolters Kluwer/Lippincott Williams \& Wilkins, Philadelphia

2. Bienkowski RS (1989) Intracellular degradation of newly synthesized collagen. Revis Biol Celular 21:423-443

3. Yamauchi M, Sricholpech M (2012) Lysine post-translational modifications of collagen. Essays Biochem 52:113-133

4. Peterkofsky B (1991) Ascorbate requirement for hydroxylation and secretion of procollagen: relationship to inhibition of collagen synthesis in scurvy. Am J Clin Nutr 54(6 Suppl):1135S-1140S

5. Phillips CL, Tajima S, Pinnell SR (1992) Ascorbic acid and transforming growth factor-beta 1 increase collagen biosynthesis via different mechanisms: coordinate regulation of pro alpha 1(I) and Pro alpha 1(III) collagens. Arch Biochem Biophys 295:397-403

6. Vadlamudi RK, McCormick RJ, Medeiros DM, Vossoughi J, Failla ML (1993) Copper deficiency alters collagen types and covalent cross-linking in swine myocardium and cardiac valves. Am J Physiol 264:H2154-H2161

7. Mimura Y, Ihn H, Jinnin M, Asano Y, Yamane K, Tamaki K (2006) Epidermal growth factor affects the synthesis and degradation of type I collagen in cultured human dermal fibroblasts. Matrix Biol 25:202-212

8. Ichiki Y, Smith EA, LeRoy EC, Trojanowska M (1997) Basic fibroblast growth factor inhibits basal and transforming growth factor-beta induced collagen alpha 2(I) gene expression in scleroderma and normal fibroblasts. J Rheumatol 24:90-95

9. Lepistö J, Peltonen J, Vähä-Kreula M, Niinikoski J, Laato M (1995) Platelet-derived growth factor isoforms PDGF-AA, -AB and $-\mathrm{BB}$ exert specific effects on collagen gene expression and mitotic activity of cultured human wound fibroblasts. Biochem Biophys Res Commun 209:393-399

10. Bird JL, Tyler JA (1994) Dexamethasone potentiates the stimulatory effect of insulin-like growth factor-I on collagen production in cultured human fibroblasts. J Endocrinol 142:571-579

11. Greenwel P, Inagaki Y, Hu W, Walsh M, Ramirez F (1997) Sp1 is required for the early response of alpha2(I) collagen to transforming growth factor-beta1. J Biol Chem 272:19738-19745

12. Kouba DJ, Chung KY, Nishiyama T, Vindevoghel L, Kon A, Klement JF, Uitto J, Mauviel A (1999) Nuclear factor-kappa B mediates TNF-alpha inhibitory effect on alpha 2(I) collagen (COL1A2) gene transcription in human dermal fibroblasts. J Immunol 162:4226-4234

13. Goldring MB, Fukuo K, Birkhead JR, Dudek E, Sandell LJ (1994) Transcriptional suppression by interleukin-1 and interferongamma of type II collagen gene expression in human chondrocytes. J Cell Biochem 54:85-99

14. Novitskiy G, Potter JJ, Rennie-Tankersley L, Mezey E (2004) Identification of a novel NF-kappaB-binding site with regulation of the murine alpha2(I) collagen promoter. J Biol Chem 279:15639-15644

15. Rippe RA, Schrum LW, Stefanovic B, Solís-Herruzo JA, Brenner DA (1999) NF-kappaB inhibits expression of the alpha1(I) collagen gene. DNA Cell Biol 18:751-761

16. Szoka L, Karna E, Palka JA (2013) UVC inhibits collagen biosynthesis through up-regulation of NF- $\kappa \mathrm{B}$ p65 signaling in cultured fibroblasts. J Photochem Photobiol B 129:143-148

17. Karna E, Nazaruk J, Szoka Ł, Pałka JA (2011) Scutellarin-dependent inhibition of collagen biosynthesis in cultured fibroblasts. Nat Prod Res 25:1789-1795

18. Goldstein RH, Poliks CF, Pilch PF, Smith BD, Fine A (1989) Stimulation of collagen formation by insulin and insulin-like growth factor-I in cultures of human lung fibroblasts. Endocrinology 124:964-970

19. Nuutinen P, Riekki R, Parikka M, Salo T, Autio P, Risteli J, Oikarinen A (2003) Modulation of collagen synthesis and mRNA by continuous and intermittent use of topical hydrocortisone in human skin. Br J Dermatol 148:39-45

20. Markova MS, Zeskand J, McEntee B, Rothstein J, Jimenez SA, Siracusa LD (2004) A role for the androgen receptor in collagen content of the skin. J Invest Dermatol 123:1052-1056

21. Philips N, Devaney J (2003) Beneficial regulation of type I collagen and matrixmetalloproteinase- 1 expression by estrogen, progesterone, and its combination in skin fibroblasts. J Am Aging Assoc 26:59-62

22. Heino $\mathbf{J}$ (2007) The collagen family members as cell adhesion proteins. BioEssays 29:1001-1010

23. Ivaska J, Reunanen H, Westermarck J, Koivisto L, Kähäri VM, Heino J (1999) Integrin alpha2beta1 mediates isoform-specific activation of $\mathrm{p} 38$ and upregulation of collagen gene transcription by a mechanism involving the alpha 2 cytoplasmic tail. J Cell Biol 147:401-416 
24. Krane SM (2008) The importance of proline residues in the structure, stability and susceptibility to proteolytic degradation of collagens. Amino Acids 35:703-710

25. Albaugh VL, Mukherjee K, Barbul A (2017) Proline precursors and collagen synthesis: biochemical challenges of nutrient supplementation and wound healing. J Nutr 11:2011-2017

26. Li P, Wu G (2018) Roles of dietary glycine, proline, and hydroxyproline in collagen synthesis and animal growth. Amino Acids 50:29-38

27. Wu G (1998) Intestinal mucosal amino acid catabolism. J Nutr 128:1249-1252

28. Tan EM, Ryhänen L, Uitto J (1983) Proline analogues inhibit human skin fibroblast growth and collagen production in culture. J Invest Dermatol 80:261-267

29. Szoka L, Karna E, Hlebowicz-Sarat K, Karaszewski J, Palka JA (2017) Exogenous proline stimulates type I collagen and HIF-1 $\alpha$ expression and the process is attenuated by glutamine in human skin fibroblasts. Mol Cell Biochem 435:197-206

30. Lowman XH, Hanse EA, Yang Y, Ishak Gabra MB, Tran TQ, Li $\mathrm{H}$, Kong M (2019) p53 promotes cancer cell adaptation to glutamine deprivation by upregulating Slc7a3 to increase arginine uptake. Cell Rep 26:3051-3060

31. Flynn NE, Bird JG, Guthrie AS (2009) Glucocorticoid regulation of amino acid and polyamine metabolism in the small intestine. Amino Acids 37:123-129

32. Phang JM (1985) The regulatory functions of proline and pyrroline-5-carboxylic acid. Curr Top Cell Regul 25:91-132

33. Yokota T, Hamauchi S, Yoshida Y, Yurikusa T, Suzuki M, Yamashita A, Ogawa H, Onoe T, Mori K, Onitsuka T (2018) A phase II study of $\mathrm{HMB} / \mathrm{Arg} / \mathrm{Gln}$ against oral mucositis induced by chemoradiotherapy for patients with head and neck cancer. Support Care Cancer 26:3241-3248

34. Phang JM, Liu W, Hancock CN, Fischer JW (2015) Proline metabolism and cancer: emerging links to glutamine and collagen. Curr Opin Clin Nutr Metab Care 18:71-77

35. Soni T, Wolfrom C, Guerroui S, Raynaud N, Poggi J, Moatti N, Gautier M (1991) Respective effects of glucose and glutamine on the glutamine synthetase activity of human skin fibroblasts. Mol Cell Biochem 102:149-154

36. Adams E, Frank A (1980) Metabolism of proline and the hydroxyprolines. Annu Rev Biochem 49:1005-1061

37. Bulus N, Cersosimo E, Ghishan F, Abumrad NN (1989) Physiologic importance of glutamine. Metabolism 38:1-5

38. Fleming GA, Steel G, Valle D, Granger AS, Phang JM (1986) The aqueous humor of rabbit contains high concentrations of pyrroline-5-carboxylate. Metabolism 35:933-937

39. Wu G, Bazer FW, Davis TA, Kim SW, Li P, Rhoads JM, Satterfield MC, Smith SB, Spencer TE, Yin Y (2009) Arginine metabolism and nutrition in growth, health and disease. Amino Acids 37:153-168

40. Ginguay A, Cynober L, Curis E, Nicolis I (2017) Ornithine aminotransferase, an important glutamate-metabolizing enzyme at the crossroads of multiple metabolic pathways. Biology (Basel) 6:18

41. Wu G, Bazer FW, Burghardt RC, Johnson GA, Kim SW, Knabe DA, Li P, Li X, McKnight JR, Satterfield MC, Spencer TE (2011) Proline and hydroxyproline metabolism: implications for animal and human nutrition. Amino Acids 40:1053-1063

42. Surazynski A, Miltyk W, Palka J, Phang JM (2008) Prolidasedependent regulation of collagen biosynthesis. Amino Acids 35:731-738

43. Surazynski A, Donald SP, Cooper SK, Whiteside MA, Salnikow K, Liu Y, Phang JM (2008) Extracellular matrix and HIF-1 signaling: the role of prolidase. Int J Cancer 122:1435-1440

44. Jaakkola P, Mole DR, Tian YM, Wilson MI, Gielbert J, Gaskell SJ, Av Kriegsheim, Hebestreit HF, Mukherji M, Schofield CJ, Maxwell PH, Pugh CW, Ratcliffe PJ (2001) Targeting of
HIF-alpha to the von Hippel Lindau ubiquitylation complex by $\mathrm{O}_{2}$-regulated prolyl hydroxylation. Science 292:468-472

45. Pandhare J, Donald SP, Cooper SK, Phang JM (2009) Regulation and function of proline oxidase under nutrient stress. J Cell Biochem 107:759-768

46. Phang JM, Liu W, Zabirnyk O (2010) Proline metabolism and microenvironmental stress. Annu Rev Nutr 30:441-463

47. Eggleston LV, Krebs HA (1974) Regulation of the pentose phosphate cycle. Biochem J 138:425-435

48. Engström W, Zetterberg A (1984) The relationship between purines, pyrimidines, nucleoside, and glutamine for fibroblast cell proliferation. J Cell Physiol 120:233-241

49. Natarajan SK, Zhu W, Liang X, Zhang L, Demers AJ, Zimmerman MC, Simpson MA, Becker DF (2012) Proline dehydrogenase is essential for proline protection against hydrogen peroxide-induced cell death. Free Radic Biol Med 53:1181-1191

50. Maxwell SS, Kochevar GJ (2008) Identification of a p53response element in the promoter of the proline oxidase gene. Biochem Biophys Res Commun 369:308-313

51. Miltyk W, Karna E, Wołczynski S, Pałka J (1998) Insulin-like growth factor I-dependent regulation of prolidase activity in cultured human skin fibroblasts. Mol Cell Biochem 189:177-184

52. Surazynski A, Miltyk W, Prokop I, Palka J (2010) Prolidase dependent regulation of TGF- $\beta$ and TGF- $\beta$ receptor expressions in human skin fibroblasts. Eur J Pharmacol 649:115-119

53. Bellon G, Chaqour B, Wegrowski Y, Monboisse JC, Borel JP (1995) Glutamine increases collagen gene transcription in cultured human fibroblasts. Biochim Biophys Acta 1268:311-323

54. Szoka L, Karna E, Andrulewicz-Botulinska E, Hlebowicz-Sarat K, Palka JA (2019) The mechanism for differential effect of nelfinavir and indinavir on collagen metabolism in human skin fibroblasts. Exp Dermatol 28:845-853

55. Hamanaka RB, O'Leary EM, Witt LJ, Tian Y, Gökalp GA, Meliton AY, Dulin NO, Mutlu GM (2019) Glutamine metabolism is required for collagen protein synthesis in lung fibroblasts. Am J Respir Cell Mol Biol 61:597-606

56. de Paz-Lugo P, Lupiáñez JA, Meléndez-Hevia E (2018) High glycine concentration increases collagen synthesis by articular chondrocytes in vitro: acute glycine deficiency could be an important cause of osteoarthritis. Amino Acids 50:1357-1365

57. Murad S, Tajima S, Johnson GR, Sivarajah S, Pinnell SR (1983) Collagen synthesis in cultured human skin fibroblasts: effect of ascorbic acid and its analogs. J Invest Dermatol 81:158-162

58. Bellon G, Monboisse JC, Randoux A, Borel JP (1987) Effects of preformed proline and proline amino acid precursors (including glutamine) on collagen synthesis in human fibroblast cultures. Biochim Biophys Acta 930:39-47

59. Karna E, Miltyk W, Wołczynski S, Palka J (2001) The potential mechanism for glutamine-induced collagen biosynthesis in cultured human skin fibroblasts. Comp Biochem Physiol B 130:23-32

60. Tanner JJ, Fendt SM, Becker DF (2018) The proline cycle as a potential cancer therapy target. Biochemistry 57:3433-3444

61. Li J, Ghazwani M, Liu K, Huang Y, Chang N, Fan J, He F, Li L, Bu S, Xie W, Ma X, Li S (2017) Regulation of hepatic stellate cell proliferation and activation by glutamine metabolism. PLoS One 12:e0182679

62. Phang JM, Downing SJ, Valle DL, Kowaloff EM (1975) A radioisotopic assay for proline oxidase activity. J Lab Clin Med $85: 312-317$

63. Holderbaum D, Ehrhart LA, McCullagh KG (1975) Effects of hyperlipoproteinemic serum and exogenous proline concentration on collagen synthesis by isolated rabbit aortas. Proc Soc Exp Biol Med 150:363-367 
64. Baich A, Chen PC, Cummings S (1980) Effect of proline on synthesis of collagen by cells in culture. Physiol Chem Phys 12:63-67

65. Forsander OA, Pikkarainen JA, Salaspuro MP (1983) A high hepatic concentration of free proline does not induce collagen synthesis in rat liver. Hepatogastroenterology 30:6-8

66. Ganapathy V, Pashley SJ, Roesel RA, Pashley DH, Leibach FH (1985) Inhibition of rat and human prolidases by captopril. Biochem Pharmacol 15:1287-1291

67. Radzicka A, Wolfenden R (1991) Analogues of intermediates in the action of pig kidney prolidase. Biochemistry 30:4160-4164

68. Gagnon C, Legault F, Geraldes P, Tanguay JF, Lambert C (2004) Diverse effects of Ace inhibitors and angiotensin II receptor antagonists on prevention of cardiac hypertrophy and collagen distribution in spontaneously hypertensive rats. Int J Cardiol 97:373-381

69. Karna E, Szoka L, Palka JA (2010) Captopril-dependent inhibition of collagen biosynthesis in cultured fibroblasts. Pharmazie 65:1-4

70. King GF, Crossley MJ, Kuchel PW (1989) Inhibition and activesite modelling of prolidase. Eur J Biochem 180:377-384

71. Davies RO, Irvin JD, Kramsch DK, Walker JF, Moncloa F (1984) Enalapril worldwide experience. Am J Med 77:23-35

72. Miltyk W, Karna E, Pałka J (1996) Inhibition of prolidase activity by non-steroid antiinflammatory drugs in cultured human skin fibroblasts. Pol J Pharmacol 48:609-613

73. Karna E, Pałka J, Wołczyński S (2001) Doxycycline-induced inhibition of prolidase activity in human skin fibroblasts and its involvement in impaired collagen biosynthesis. Eur J Pharmacol 430:25-31

74. Muszyńska A, Wolczyński S, Pałka J (2001) The mechanism for anthracycline-induced inhibition of collagen biosynthesis. Eur J Pharmacol 411:17-25

75. Szoka L, Karna E, Nazaruk J, Palka JA (2016) Prolidase-dependent mechanism of (Z)-8,9-epoxyheptadeca-1,11,14-triene-induced inhibition of collagen biosynthesis in cultured human skin fibroblasts. Nat Prod Res 30:665-671

76. Karna E, Miltyk W, Pałka JA (2006) Butyrate-induced collagen biosynthesis in cultured fibroblasts is independent on $\alpha_{2} \beta_{1}$ integrin signalling and undergoes through IGF-I receptor cascade. Mol Cell Biochem 286:147-152

77. Karna E, Miltyk W, Pałka JA, Jarzabek K, Wołczyński S (2006) Hyaluronic acid counteracts interleukin-1-induced inhibition of collagen biosynthesis in cultured human chondrocytes. Pharmacol Res 54:275-281

78. Karna E, Szoka L, Palka JA (2013) The mechanism of hydralazine-induced collagen biosynthesis in cultured fibroblasts. Naunyn Schmiedebergs Arch Pharmacol 386:303-309

79. Szoka L, Karna E, Palka J (2015) The mechanism of oxythiamineinduced collagen biosynthesis in cultured fibroblasts. Mol Cell Biochem 403:51-60

80. Galicka A, Nazaruk J (2007) Stimulation of collagen biosynthesis by flavonoid glycosides in skin fibroblasts of osteogenesis imperfecta type I and the potential mechanism of their action. Int J Mol Med 20:889-995

81. Myara I, Miech G, Fabre M, Mangeot M, Lemonnier A (1987) Changes in prolinase and prolidase activity during $\mathrm{CCl}_{4}$ administration inducing liver cytolysis and fibrosis in rat. Br J Exp Pathol 68:7-13

82. Türkbeyler I, Demir T, Pehlivan Y, Kaplan DS, Ceribasi AO, Orkmez M, Aksoy N, Taysi S, Kisacik B, Onat AM (2012) Prolidase could act as a diagnosis and treatment mediator in lung fibrosis. Inflammation 35:1747-1752

83. Demirbag R, Yildiz A, Gur M, Yilmaz R, Elçi K, Aksoy N (2007) Serum prolidase activity in patients with hypertension and its relation with left ventricular hypertrophy. Clin Biochem 40:1020-1025

84. Dunn R, Dolianitis C (2008) Prolidase deficiency: the use of topical proline for treatment of leg ulcers. Australas J Dermatol 49:237-238

85. Milligan A, Graham-Brown RAC, Burns DA, Anderson I (1989) Prolidase deficiency: a case report and literature review. Br J Dermatol 121:405-409

86. Leoni A, Cetta G, Tenni R, Pasquali-Ronchetti I, Bertolini F, Guerra D, Dyne K, Castellani A (1987) Prolidase deficiency in two siblings with chronic leg ulcerations. Clinical, biochemical and morphological aspects. Arch Dermatol 123:493-499

87. Arata J, Kenichi H, Takashi O (1986) Effect of topical application of glycine and proline on recalcitrant leg ulcers of prolidase deficiency. Arch Dermatol 122:626-627

88. Jemec GB, Moe AT (1996) Topical treatment of skin ulcers in prolidase deficiency. Pediatr Dermatol 13:58-60

89. Ortega García MP, Cánoves Escolano MA, Blasco Segura P, García Melgares ML (2006) Effective therapy with a glycineproline ointment in a patient with recurrent ulcers from prolidase deficiency. Farm Hosp 30:304-308

90. Freij BJ, Levy HL, Dudin G, Mutasim D, Deeb M, Der Kaloustian VM (1984) Clinical and biochemical characteristics of prolidase deficiency in siblings. Am J Med Genet 19:561-571

91. Karna E, Pałka J, Chyczewski L, Słodkowska J, Bogdan J (1997) Prolidase and prolinase activities in moderately and poorly differentiated lung adenocarcinoma. Rocz Akad Med Bialymst 42:230-240

92. Galicka A, Wolczynski S, Anchim T, Surazynski A, Lesniewicz R, Palka J (2001) Defects of type I procollagen metabolism correlated with decrease of prolidase activity in a case of lethal osteogenesis imperfecta. Eur J Biochem 268:2172-2178

93. Karna E, Miltyk W, Surazyński A, Pałka JA (2008) Protective effect of hyaluronic acid on interleukin-1-induced deregulation of beta1-integrin and insulin-like growth factor-I receptor signaling and collagen biosynthesis in cultured human chondrocytes. Mol Cell Biochem 308:57-64

94. Palka JA, Phang JM (1997) Prolidase activity in fibroblasts is regulated by interaction of extracellular matrix with cell surface integrin receptors. J Cell Biochem 67:166-175

95. Miltyk W, Karna E, Pałka JA (2007) Prolidase-independent mechanism of camptothecin-induced inhibition of collagen biosynthesis in cultured human skin fibroblasts. J Biochem 141:287-292

96. Karna E, Pałka JA (2008) Phosphoenolpyruvate-dependent inhibition of collagen biosynthesis, $\alpha 2 \beta 1$ integrin and IGF-I receptor signaling in cultured fibroblasts. Mol Cell Biochem 315:61-67

Publisher's Note Springer Nature remains neutral with regard to jurisdictional claims in published maps and institutional affiliations. 